\title{
Technetium-99m Pharmaceuticals: Preparation and Quality Control in Nuclear Medicine
}

I. Zolle, ed.

New York, NY: Springer, 2007, 345 pages, $\$ 169$

Written by a panel of 21 experts in the field and edited by Ilse Zolle, this hardbound volume is the current authoritative desk reference for those working with ${ }^{99 \mathrm{~m}} \mathrm{Tc}$-labeled radiopharmaceuticals. The 11 chapters of part 1 provide concise, but comprehensive and well-referenced, accounts of the chemistry of technetium and its ligands, the design of biologically active ${ }^{99 \mathrm{~m}} \mathrm{Tc}$-labeled conjugates, the preparation and quality control of ${ }^{99 \mathrm{~m}} \mathrm{Tc}-$ labeled radiopharmaceuticals, the particulars of generators and sterile kit formulations, and the regulatory aspects of radiopharmaceutical manufacture from the European viewpoint. Part 2 comprises 11 main monographs that cover the ${ }^{99 \mathrm{~m}} \mathrm{Tc}$-labeled radiopharmaceuticals that are widely used in nuclear medicine. Pertechnetate; colloids; brain and heart perfusion agents; bone, renal, and hepatobiliary agents; and labeled peptides, proteins, antibodies, and cells are covered in depth. The monographs include details on chemistry, trade names, kit components, preparation, formulation, storage, stability, and quality control. Each monograph also includes sections on clinical pharmacokinetics, radiation dosimetry, and the most common clinical applications. These monographs are organized for ready retrieval of information and include pertinent primary references. Case studies and clinical nuance are beyond the scope of this work, which is an outgrowth of the European Working Group on the Quality Control of ${ }^{99 \mathrm{~m} T c-\text { Radio- }}$ pharmaceuticals. Forewords by Drs. Henry Wagner and Christoph Reiners provide perspective, and appendices on pediatric radiopharmacy round out the text.

This nicely organized and clearly illustrated book provides an up-to-date resource for radiopharmacists and nuclear medicine physicians who compound and prescribe ${ }^{99 \mathrm{~m}} \mathrm{Tc}$-labeled radiopharmaceuticals. Radiochemists and those concerned with regulatory affairs also will be interested, and the book could be used as a primary text in nuclear medicine training programs. This outstanding book fills a void and is the first compilation of its kind in many years. We recommend it with the highest enthusiasm.

Susan Z. Lever

John R. Lever University of Missouri Columbia, Missouri

COPYRIGHT (C) 2009 by the Society of Nuclear Medicine, Inc.

DOI: 10.2967/jnumed.109.062166 